\title{
CEOP Regimen
}

National Cancer Institute

\section{Source}

National Cancer Institute. CEOP Regimen. NCI Thesaurus. Code C160564.

A chemotherapy regimen consisting of cyclophosphamide, etoposide, vincristine and prednisone that can be used in the treatment of non-Hodgkin lymphoma (NHL). 